\title{
Non-invasive Imaging of Stem Cells by Scanning Ion Conductance Microscopy: Future Perspective
}

\author{
Julia Gorelik, Ph.D., ${ }^{1}$ Nadire N. Ali, Ph.D., ${ }^{1}$ Siti H. Sheikh Abdul Kadir, M.Sc., ${ }^{1}$ Max Lab, Ph.D., ${ }^{2}$ \\ Petra Stojkovic, Ph.D., ${ }^{3,{ }^{*}}$ Lyle Armstrong, Ph.D., ${ }^{3}$ Elena V. Sviderskaya, Ph.D., ${ }^{4}$ Yuri A. Negulyaev, Ph.D., ${ }^{5}$ \\ David Klenerman, Ph.D., ${ }^{6}$ Dorothy C. Bennett, Ph.D., ${ }^{4}$ Majlinda Lako, Ph.D., ${ }^{3}$ Sian E. Harding, Ph.D., ${ }^{1}$ \\ Miodrag Stojkovic, Ph.D., ${ }^{3, *}$ and Yuri E. Korchev, Ph.D. ${ }^{2}$
}

The most valuable property of stem cells (SCs) is their potential to differentiate into many or all cell types of the body. So far, monitoring SC differentiation has only been possible after cells were fixed or destroyed during sample preparation. It is, however, important to develop nondestructive methods of monitoring SCs. Scanning ion conductance microscopy (SICM) is a unique imaging technique that uses similar principles to the atomic force microscope, but with a pipette for the probe. This allows scanning of the surface of living cells noninvasively and enables measurement of cellular activities under more physiological conditions than is possible with other high-resolution microscopy techniques. We report here the novel use of the SICM for studying SCs to assess and monitor the status of SCs and various cell types differentiated from SCs.

\section{Introduction}

A LTHOUGH AN APPRECIATION of the functional importance of embryonic stem cells (ESCs) is increasing almost exponentially, monitoring of ESC differentiation needs improvement. This is despite techniques such as flow cytometry, cytomics, proteomics, and genomics, which are making significant inroads in understanding and characterizing ESC cultures. ${ }^{1-3}$ ESCs, derived from the inner cell mass of early stage of embryonic development, can self-renew and potentially differentiate into all cell types of the body. ${ }^{4}$ They can also serve as experimental models for the study of early embryonic development and differentiation, and may provide sources for cell therapy of various tissues and organs. However, despite this potential, their study so far usually involves cell fixation or destruction during sample preparation, and incorporate complex and laborious techniques.

The culture of human embryonic stem cells (hESCs) is also still challenging and involves manual dissection and elimination of differentiated cells. Current methods are based on the observation of cultures under phase contrast microscope, and these can lead to errors in interpretation. Further, unless cells have been genetically modified to include a reporter gene driven by a pluripotency gene promoter (e.g., Oct-4green fluorescent protein [GFP]), it is sometimes difficult to assess the cultures. ${ }^{5}$

Moreover, it is often necessary to derive differentiated cells from ESCs, and in most cases cell differentiation in culture does not occur simultaneously, leaving a heterogeneous mixture of differentiated cell types. ${ }^{6}$ The determination of the state of differentiation of ES-derived cells is thus also challenging. Although methods such as polymerase chain reaction (PCR) and proteomics are used with mixed cell populations, ${ }^{7}$ there is a shortage of methods that can determine the phenotype and functional activity of individual cells within these populations, especially live cells as they grow and differentiate.

More non-invasive methods for monitoring ESC differentiation are required, preferably rapid ones and which are applicable to live cells. We present here a method to monitor both undifferentiated and differentiated states of individual SCs in live cultures using the scanning ion conductance microscopy (SICM). ${ }^{8,9}$ This is a unique imaging technique that uses similar principles to the atomic force microscope, but in contrast to physically tapping the preparation with a sharp tip, the SICM uses a noncontact nanopipette for the probe. ${ }^{9,10}$

\footnotetext{
${ }^{1}$ National Heart and Lung Institute, Imperial College London, London, United Kingdom.

${ }^{2}$ Division of Medicine, Imperial College London, London, United Kingdom.

${ }^{3}$ Centre for Stem Cell Biology and Developmental Genetics, University of Newcastle Upon Tyne, Newcastle, United Kingdom.

${ }^{4}$ Division of Basic Medical Sciences, St. George's, University of London, London, United Kingdom.

${ }^{5}$ Institute of Cytology, Russian Academy of Sciences, St.-Petersburg, Russia.

${ }^{6}$ Department of Chemistry, Cambridge University, Cambridge, United Kingdom.

*Present address: Centro de Investigación, C/E.P. Avda. Autopista del Saler 16-3 (Junto Oceanografico), Valencia, Spain.
} 
This allows high-resolution, non-invasive probing of the surface of unfixed cells. Fixed pipette-sample distance is maintained by reduction in ion flow as the pipette approaches the sample. SICM has been used to image living cell surfaces and their dynamics down to the level of individual protein complexes, ${ }^{11}$ and determine the dynamics of microvilli of epithelial cells and how they assemble to produce more complex structures. ${ }^{12}$ In this paper SICM is used to study individual SCs to monitor their status in time and identify the various cell types differentiated from SCs.

\section{Materials and Methods}

\section{Growth of hESCs}

Two different hESC lines were used: hES-NCL1 and H7. hES-NCL1 cells were grown as described previously ${ }^{13}$ on mouse embryonic fibroblasts (MEFs) until passages 43 and 47 , respectively, and then transferred onto tissue culture plates (http://www.nuncbrand.com; Nunc, Roskilde, Denmark) precoated with human serum (HS) (Cat. No. H1388; Sigma-Aldrich, Dorset, UK). According to the manufacturer, HS had been derived from male clotted blood (all from the United States) tested and found negative for hepatitis B surface antigen, anti-hepatitis $\mathrm{C}$ virus, and anti-HIV/HIV-2 by U.S. Food and Drug Administration-approved tests. To coat plates with HS, their surfaces were overlaid with HS for $1 \mathrm{~h}$ at room temperature. Thereafter, HS was removed, and plates were dried for $1 \mathrm{~h}$ at room temperature. Colonies of hESCs were grown on HS in the presence of medium conditioned by the fibroblasts derived from differentiated hESCs (hES-dF), and medium was changed every $48 \mathrm{~h}$. hESC colonies were disaggregated mechanically every 4-6 days and freshly re-plated. ${ }^{13}$

To study the distribution of specific cell-surface marker of undifferentiated hESCs on the cell surface, we performed live immunocytochemical staining of the hESCs cell-surface markers SSEA-4 (1:100) and TRA-1-60 (www.chemicon.com; Chemicon, Temecula, CA). First antibodies were added to hESCs for $20 \mathrm{~min}$ at $37^{\circ} \mathrm{C}$. The samples were gently washed three times with ES-medium before being incubated with the secondary antibodies (Sigma) conjugated to ALEXA Fluor488 at $37^{\circ} \mathrm{C}$ for $20 \mathrm{~min}$.

For Nanog, staining cells were fixed with $4 \%$ paraformaldehyde for $10 \mathrm{~min}$ and then permeabilized/blocked with $0.1 \%$ Triton $\mathrm{X}-100$ and $5 \%$ fetal calf serum (FCS) in phosphate-buffered saline (PBS) at room temperature for $45 \mathrm{~min}$. After blocking, the cells were incubated at room temperature for $1 \mathrm{~h}$ with Nanog (1:20; R\&D Systems, Abingdon, United Kingdom) antibody. The cells were washed with 5\% FCS and PBS before addition of the secondary antibody: rhodamine-conjugated anti-goat immunoglobulin G (1:100; http://www.jacksonimmuno.com; Jackson Immuno Research, West Grove, PA) for Nanog as previously described. ${ }^{14}$ All samples were again washed three times with ES medium and subjected to surface confocal microscopy or to optical microscopy using a Zeiss microscope (Carl Zeiss Ltd., Welwyn Garden City, United Kingdom).

\section{Spontaneous differentiation of hES-NCL1 cells}

Colonies of hES-NCL1 cells grown on HS and in the presence of hES-dF-conditioned medium were re-plated on new HS-coated plates in hES-dF-conditioned medium as previously described. ${ }^{13}$ After 5-12 days without passaging, spontaneous differentiation was observed, and differentiated cells were re-plated and cultured under the same conditions.

Neuron-like cells were loaded by fluorescent dye N(3-triethylammoniumpropyl)-4(4-(dibutylamino)styryl) pyridinium dibromide (FM1-43) with incubation of $20 \mu \mathrm{M}$ FM1-43 in a solution containing an additional $50 \mathrm{mM}$ potassium chloride $(\mathrm{KCl})$ for $90 \mathrm{~s}$. After washing cells, they were incubated at $37^{\circ} \mathrm{C}$ for $15 \mathrm{~min}$. Experiments were then performed at room temperature $\left(25-28^{\circ} \mathrm{C}\right)$.

All samples were imaged by surface confocal microscopy. Other neuron-like cells were fixed in $4 \%$ paraformaldehyde in PBS (Sigma) for $30 \mathrm{~min}$ and then permeabilized for an additional $10 \mathrm{~min}$ with $0.1 \%$ Triton $\mathrm{X}$ (Sigma). The blocking step was $30 \mathrm{~min}$ with $2 \%$ FCS in PBS. Differentiated cells were incubated with antibody against tubulin III (1:100; Chemicon) antibody was detected using corresponding secondary antibodies conjugated to fluorescein-iso-thiocyanate (FITC).

\section{Reverse transcription-PCR analysis}

Reverse transcription (RT)-PCR was done using the cells to cDNA II kit (http://www.ambion.com; Ambion, Huntingdon, UK). hESCs were submerged in $100 \mu \mathrm{L}$ of ice-cold cell lysis buffer and lysed by incubation at $75^{\circ} \mathrm{C}$ for $10 \mathrm{~min}$. Genomic DNA was degraded by incubation with DNAse I for $15 \mathrm{~min}$ at $37^{\circ} \mathrm{C}$. RNA was reverse transcribed using Moloney murine leukemia virus RT and random hexamers following the manufacturer's instruction. PCR was carried out, and the products were run on $2 \%$ agarose gels and stained with ethidium bromide. Results were assessed on the presence of the appropriate-size PCR products as previously described. $^{13}$ Neuronal primers were used as previously described. ${ }^{15}$

\section{Maintenance, propagation, and differentiation of human H7 ESCs}

All tissue culture reagents were purchased from GibcoInvitrogen (Paisley, Scotland) unless otherwise stated. Plastic consumables were from Fisher Scientific (Loughborough, United Kingdom, www.fisher.co.uk). hESCs (H7 line), supplied by Geron Corporation (Menlo Park, CA), were cultured on Matrigel-coated six-well plates in MEF-conditioned medium (MEF-CM), supplemented by $8 \mathrm{ng} / \mathrm{mL}$ recombinant human basic fibroblast growth factor (bFGF) and antibiotics (50 U/mL penicillin and $50 \mu \mathrm{L} / \mathrm{mL}$ streptomycin).

All procedures for producing MEF-CM in the presence of $4 \mathrm{ng} / \mathrm{mL}$ bFGF, the subculturing of the $\mathrm{H} 7$ cells, and their differentiation via embryo bodies (EBs) were as described by Geron (http://www.geron.com/PDF/scprotocols.pdf), with the exception that mitomycin $C$, rather than irradiation, was used for mitotic inactivation of the MEFs. Briefly, after their isolation from 13-day embryos of MF-1 strain of mice, MEFs were expanded in culture and inactivated at passage 3 . After overnight attachment of $12 \times 10^{6}$ inactive cells in $15 \%$ FCS (nonheat inactivated) containing medium, the cells were washed and cultured in medium referred to as "human ES cell medium" supplemented by $4 \mathrm{ng} / \mathrm{mL}$ bFGF. The human ES cell medium was made up of KO-Dulbecco's modified Eagle's medium, supplemented by $20 \%$ serum replacement 
(KOSR), $1 \mathrm{mM}$ L-glutamine, $0.1 \mathrm{mM}$ nonessential amino acids, $0.1 \mathrm{mM} \beta$-mercaptoethanol, and antibiotics $(50 \mathrm{U} / \mathrm{mL}$ penicillin and $50 \mu \mathrm{M} / \mathrm{mL}$ streptomycin). MEF-CM $(150 \mathrm{~mL})$ was collected daily from each T225 flask pooled, filtered, and aliquoted for storage at $-20^{\circ} \mathrm{C}$. Undifferentiated $\mathrm{H} 7$ cells were fed with MEF-CM daily with further addition of $8 \mathrm{ng} / \mathrm{mL}$ bFGF.

Before either splitting or differentiation into cardiomyocytes, cultures of $\mathrm{H7}$ cells were subjected to $5-10 \mathrm{~min}$ of treatment with collagenase IV $(200 \mathrm{U} / \mathrm{mL} ; 1 \mathrm{~mL} /$ well $)$ at $37^{\circ} \mathrm{C}$, followed by mechanical dislodgement. To induce differentiation via EBs, colonies of undifferentiated H7 cells were broken up mechanically into smaller clusters by scraping the well with the tip of a 5-mL pipette, followed by pipetting and culture in suspension in low adherence plates. The differentiation medium was ES cell medium in which $20 \%$ KOSR was replaced by $20 \%$ nonheat-inactivated FCS. After 4 days, EBs of varying sizes were plated out onto $0.5 \%$ gelatin-coated glass or plastic and studied at time periods from day 9 to day 12 of differentiation onward.

\section{Neural crest-like SCs}

We used neural crest-like SCs obtained from neonatal mouse epidermis. These cells resemble neural crest SCs in their apparent capacity to differentiate into several cell types normally derived from the neural crest. They can produce Schwann precursor cells, functional melanocytes, and functional neurons (Sviderskaya et al., submitted to FASEB J).

We used one of the three independently established lines called neural crest-like cells-misty, line 6 (nc-m6). The undifferentiated cells were grown in RPMI 1640 medium supplemented with penicillin, streptomycin, glutamine $(2 \mathrm{mM})$, newborn-calf serum $(10 \%)$, and 12-O-tetradecanoyl phorbol acetate (TPA, $2 \mathrm{nM})$. Incubation was with $10 \% \mathrm{v} / \mathrm{v} \mathrm{CO}_{2}$ at $37^{\circ} \mathrm{C}$. For the experiments described, the cells were plated at $4 \times 10^{4}$ cells $/ \mathrm{mL}$ and grown in RPMI medium supplemented with penicillin, streptomycin, glutamine $(2 \mathrm{mM})$, FCS $(10 \%)$, TPA $(2 \mathrm{nM})$, transforming growth factor $\beta 1(120 \mathrm{pM})$, endothelin-1 $(10 \mathrm{nM})$, fibroblast growth factor-2 $(40 \mathrm{pM})$, and neuregulin1- $\beta 1(10 \mathrm{nM})$ for 2 weeks.

Neural crest-like SCs were loaded by FM1-43 with incubation of $20 \mu \mathrm{M}$ FM1-43 in a solution containing an additional $50 \mathrm{mM} \mathrm{KCl}$ for $90 \mathrm{~s}$. After washing cells, they were incubated at $37^{\circ} \mathrm{C}$ for $15 \mathrm{~min}$. Experiments were then performed at room temperature $\left(25-28^{\circ} \mathrm{C}\right)$.

\section{Outside out voltage-clamp recording from neural crest-like SCs}

Outside out patch-clamp recordings were conducted at room temperature $\left(21^{\circ} \mathrm{C}\right)$ using a MultiClamp 700B amplifier and the Clampex 9.2 program (both by Molecular Devices, Sunnyvale, CA). Fire-polished electrodes (2.52.7 Mohm) were fabricated from 1.0-mm borosilicate glass capillaries (Intracel, Herts, United Kingdom) using a P-2000 Puller (Sutter Instrument, Novato, CA). The pipette solution contained (in $\mathrm{mM}$ ) the following: $140 \mathrm{CsF}, 1$ ethylene glycol-bis (2-amino-ethyl)-N,N, $\mathrm{N}^{\prime}, \mathrm{N}^{\prime}$-tetraacetic acid (EGTA), 10 sodium chloride, and 10 HEPES, $\mathrm{pH}$ 7.3. The standard bathing solution was (in $\mathrm{mM}$ ) 140 sodium chloride, $3 \mathrm{KCl}$, 1 magnesium chloride, 1 calcium chloride, and 10 HEPES, $\mathrm{pH}$ 7.3.
The use of internal fluoride facilitates inhibition of high voltage-activated $\mathrm{Ca}^{2+}$ currents $^{16-18}$ and helps to reveal tetrodotoxin-resistant (TTX-R) currents. ${ }^{19,20}$ The pipette potential was zeroed before seal formation, and voltages were not corrected for liquid junction potential. Extracellular media were exchanged using a gravity-fed bath perfusion system at a flow rate of $10 \mathrm{~mL} / \mathrm{min}$, while bath solution was removed by continuous suction. The volume of fluid in the recording chamber was $1 \mathrm{~mL}$, allowing the exchange of bathing solution within 6-8s.

\section{Data analysis}

The electrophysiological data were analyzed using the Clampfit 9.2 (Molecular Devices) and ORIGIN 5.0 (Microcal Software, Northampton, MA) software programs.

\section{SICM}

Topographic imaging of the cell was performed using SICM methods. ${ }^{9}$ Briefly, the pipette mounted on a piezo stage is moved over the cell while maintaining a fixed distance from the surface (Fig. 1A). This is achieved by a feedback control keeping the ion current flowing through the pipette to the cell surface constant. Scanning surface confocal microscopy (SSCM) is based on a combination of scanning confocal microscope and SICM. In SSCM the cell is moved up and down in the $z$ direction while scanned in the $x$ and $y$ directions, so its surface is always the same distance from the nanopipette (typically, $25-75 \mathrm{~nm}$ ). A laser beam is passed up a high numerical aperture objective to focus just at the tip of the nanopipette, and a pinhole is positioned at the image plane so that the confocal volume is just below the pipette (Fig. 1A). ${ }^{21}$ Thus, fluorescence image of the cell surface is obtained in a single scan, as well as simultaneously captured image of the cell topography. ${ }^{22}$

For study of hESC-derived cardiomyocytes (ESCMs), we performed imaging of various ESCM layer zones and identified contracting cardiomyocytes. ${ }^{23}$ To investigate the changes in rate and rhythm of cardiomyocyte contraction, we recorded the vertical cell displacement of individual cells using the SICM as described previously. ${ }^{21}$ As the cell surface rises during contraction, the micropipette is displaced vertically. This measurement allows alterations in contraction to be recorded (Fig. 3D).

For patch clamping (after imaging the surface if required), the pipette is vertically lowered under piezo control until contact with the cell surface is made, usually after moving down by one tip radius $(100 \mathrm{~nm})$. The gigaseal is made using conventional methodology (pipette suction). ${ }^{24,25}$

\section{Results and Discussion}

\section{Study of undifferentiated ESCs: quality control of $h E S C$ cultures}

We imaged the surface of undifferentiated cells from the hES-NCL1 line (Fig. 1). Figure $1 \mathrm{~B}$ and $1 \mathrm{C}$ shows an image selected from a time-lapse observation of undifferentiated cells from the hES-NCL1 line growing on HS (each scan took $17 \mathrm{~min}$ ). We also present a movie from a $9 \mathrm{~h}$ scanning (Supplemental Movie S1, available online at www .liebertonline.com/ten). Figure $1 \mathrm{~B}$ and $1 \mathrm{C}$ shows cilia and microvilli on the surface of hESCs grown on HS. While the 

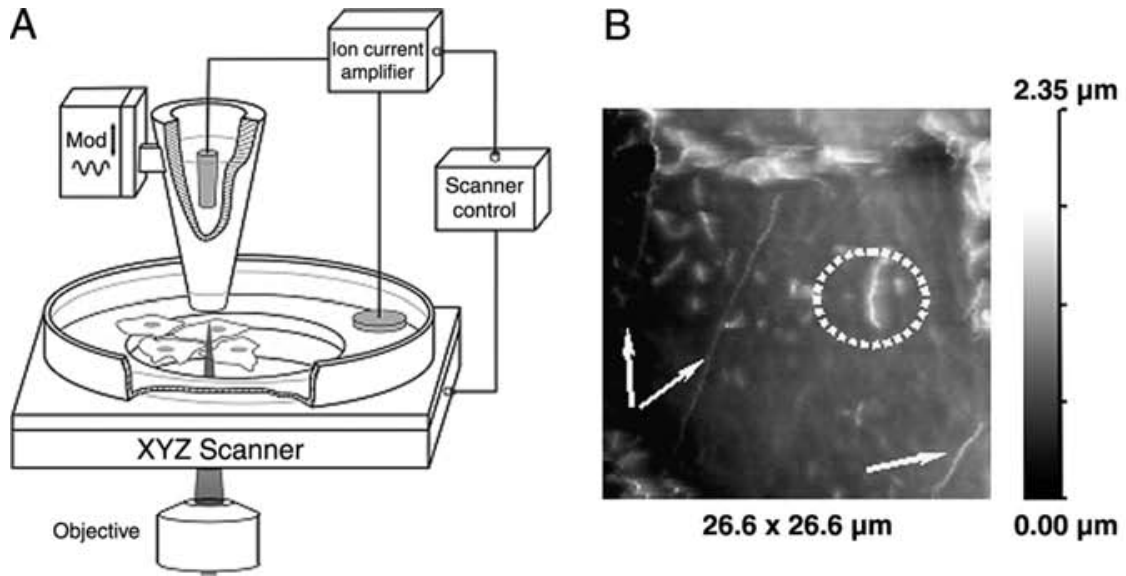

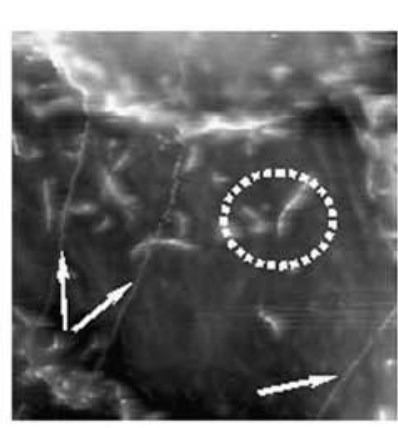

$26.6 \times 26.6 \mu \mathrm{m}$
$1.59 \mu \mathrm{m}$

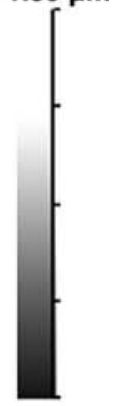

$0.00 \mu \mathrm{m}$

FIG. 1. (A) Principal scheme of SSCM. (B, C) Examples of surface structures on undifferentiated hESC-NCL1. Image selected from a time-lapse observation of undifferentiated hESCs from NCL1 line growing on HS (each scan took 17 min). Cilia were seen on the surface of hESCs grown on HS. The two images show that while microvilli (in the dotted oval) move, cilia (arrows) remain stable on the surface of cells.

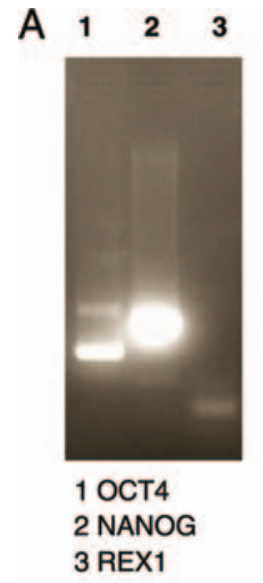

C

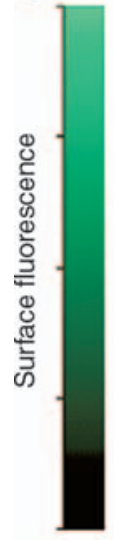

B
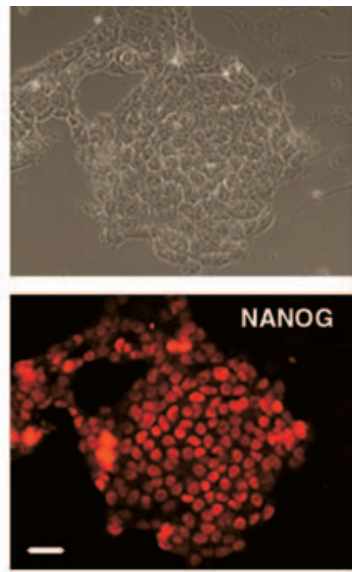
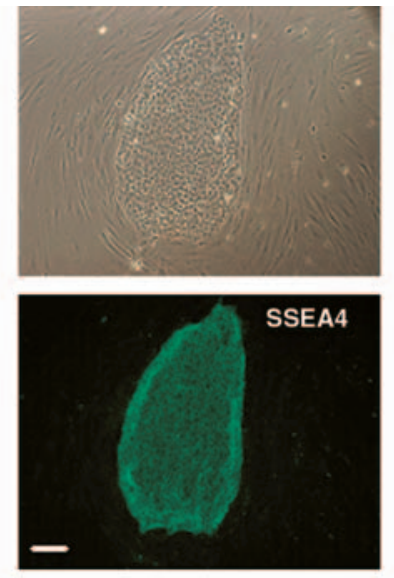
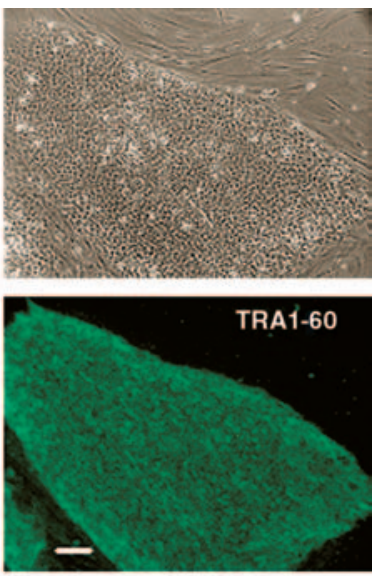

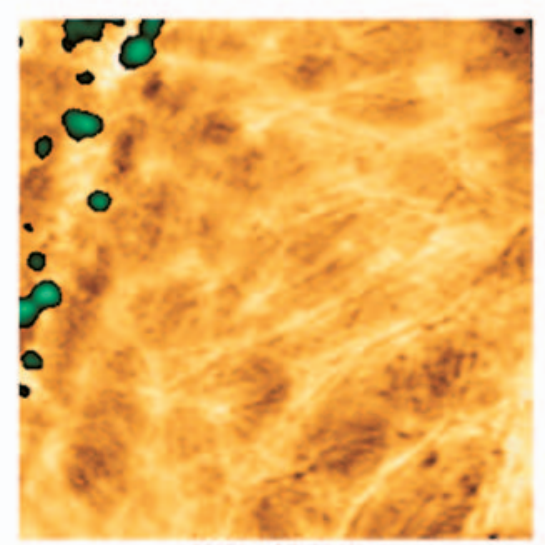

$40.0 \times 40.0 \mu \mathrm{m}$
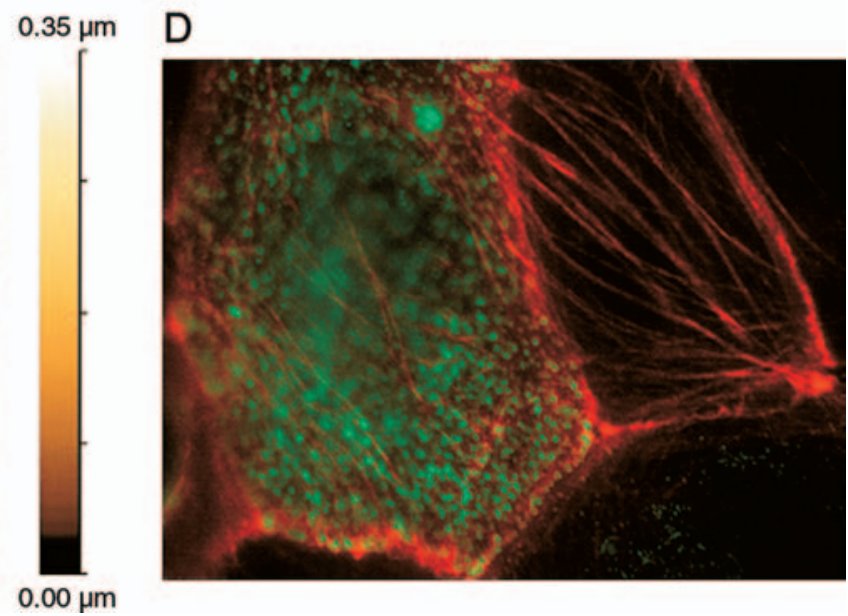

FIG. 2. Quality control of undifferentiated hES-NCL1 cells. (A) RT-PCR analysis of undifferentiated hES-NCL1 cells. (B) hES-NCL1 cells stained with antibody recognizing the Nanog, TRA-1-60, and SSEA-4. Scale bars: $25 \mu \mathrm{m}$. (C) Monitoring hESCs in culture as they grow to identify cells that started to differentiate, therefore have lost the characteristic microvillus structure. Live imaging. Overlay of simultaneously obtained topographic and surface-confocal fluorescence images (SSEA-4) of hESCs from NCL1 line growing on HS. The picture shows two cells. The cell on the right has elongated structures on the surface, perhaps reflecting underlying actin bundles, and is SSEA-4 negative. The cell on the left of the picture has microvilli that colocalized with SSEA-4. Immunostaining confirmed that hESCs that had lost microvilli and attained prominent cytoskeletal structures are indeed the cells that have differentiated. (D) Cells on the same coverslip after fixation and conventional double staining with anti-SSEA-4 (green) and rhodamine phalloidin (red). The cell with actin bundles is SSEA-4 negative. Immunostaining confirmed that hESCs that had lost microvilli and attained prominent cytoskeletal structures are indeed the cells that have differentiated. Color images available online at www.liebertonline.com/ten. 
A

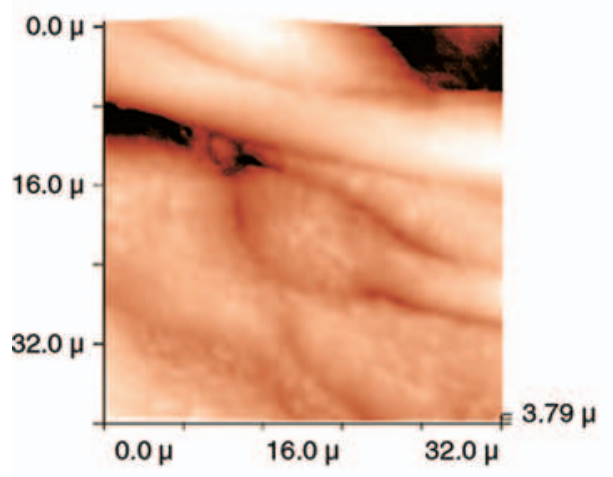

B

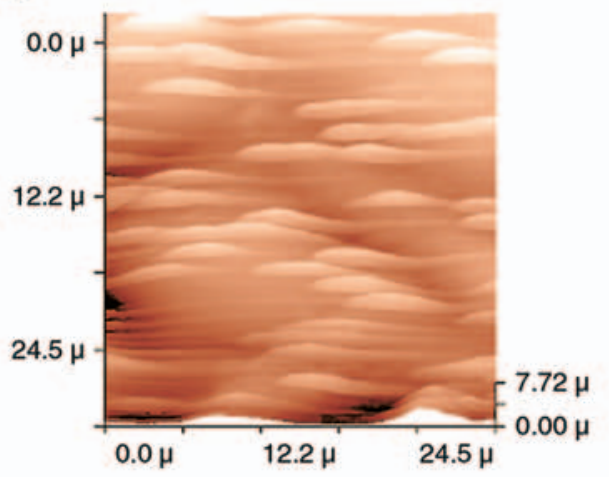

C

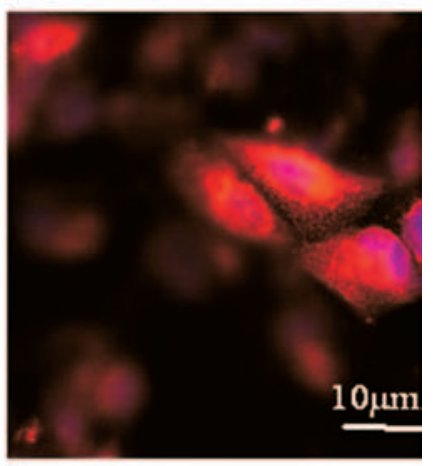

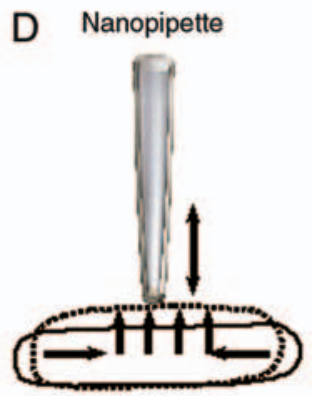

Cardiomyocyte
E

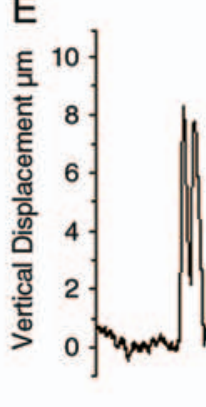

Doxorubucin

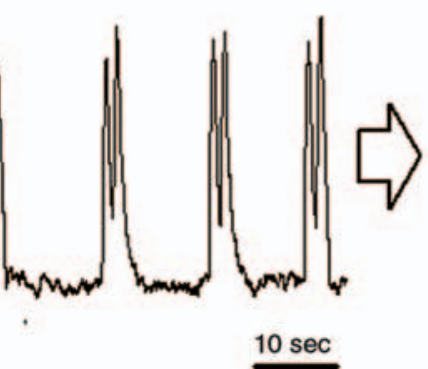

F

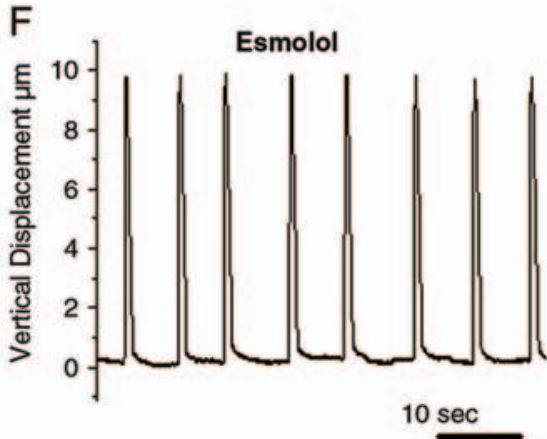

FIG. 3. Identification of ESCMs in mixed cultures using SICM. Three-dimensional reconstruction of the SICM image of the surface of a noncontracting cell from the same culture. Three-dimensional reconstruction of the SICM image of the surface of a contracting ESCMs (H7 line) after 18 days in culture. (C) Differentiating hESCs (H7 line) similar to (A) and (B) stained with anticardiac MHC, followed by Alexa 568-conjugated secondary antibodies and counterstained with 4,6-Diamidino-2phenylindole dihydrochloride (DAPI). Note that only a fraction of the cells are positive for the cardiomyocyte marker. (D) Schema of measurement of vertical displacement of cardiomyocyte. (E, F) Recording of contraction of single ESCM. Addition of doxorubicin $(100 \mu \mathrm{g} / \mathrm{mL})$ induces arrhythmia $(\mathbf{E})$, and subsequent addition of esmolol $(1 \mu \mathrm{g} / \mathrm{mL})$ restores rhythmic contractions (F). Color images available online at www.liebertonline.com/ten.

microvilli (in the dotted oval) move, the cilia (white arrows) remain stationary on the cell surface.

Undifferentiated cells expressed Oct-4, Nanog, and Rex-1 as revealed by RT-PCR analysis (Fig. 2A). They also were positive for several known markers of SCs, namely, TRA-160, SSEA-4, and Nanog, when stained with corresponding antibodies (Fig. 2B).

Using the combination of SICM with confocal microscopy, we mapped specific cell-surface marker for undifferentiated hESCs, after staining with appropriate antibodies (e.g., SSEA-4) and localized these markers on specific cell structures. We monitored hESCs in culture as they grew and found cells that started to differentiate also lost their characteristic microvillar structures. Figure 2C shows overlay of simultaneously obtained topographic and surface-confocal fluorescence images for SSEA-4 of hESCs from NCL1 line growing on HS. The figure shows two cells. The cell on the right has elongated structures on the surface, perhaps reflecting underlying actin bundles, and is SSEA-4 negative. The cell on the left has microvilli that colocalized with SSEA4. Figure 2A represents the cells on the same coverslip after fixation and double staining with anti-SSEA-4 and rhodamine phalloidin. The cell with actin bundles is SSEA-4 negative. Immunostaining confirmed that hESCs that had lost microvilli and attained prominent cytoskeletal structures are indeed the cells that have differentiated. Using immunohistochemistry and immunoscanning electron microscopy, Cui et al. showed that SSEA-1 was located preferentially on the edge of low protuberances and microvilli in mouse ESCs. ${ }^{26}$ Also immunostaining confirmed that hESCs that had lost microvilli and attained prominent cytoskeletal structures are indeed the cells that have differentiated. Our observations are in agreement with previous findings of Krtolica et al., who have seen the disappearance of microvilli on hESCs that underwent differentiation by confocal microscopy and electron microscopy. ${ }^{27}$

We can scan live hESCs for several days and monitor how the surface features change as the cells differentiate.

\section{Study of ESCMs}

Using SICM, we can identify individual ESCMs in a beating cluster among mixed population of differentiating cells and make measurements of contractile activity from those ESCMs. ${ }^{23}$ We produced a scan of a layer of differentiating hESCs, and were able to locate individual beating ESCMs (Fig. 3). Figure 3A shows a three-dimensional reconstruction of the SICM image of the surface of noncontracting cells from the $\mathrm{H} 7$ line after 18 days in culture. Figure 3B shows a three-dimensional reconstruction of the 
FIG. 4. Evaluation of neuronal differentiation of neural crest-like SCs using SICM.

(A) Photograph of the experimental arrangement with positioned pipette on the dendrite of the neural crestlike SCs. (B) Single channel recording (outside out) of cationic sodium-like channel from pluripotent neural crestlike SC line. (C, D) Active synapses in sensory neurons derived from pluripotent neural crest-like SC line from neonatal mouse epidermis. Cells were loaded with FM143 dye. Color images available online at www.liebertonline .com/ten.

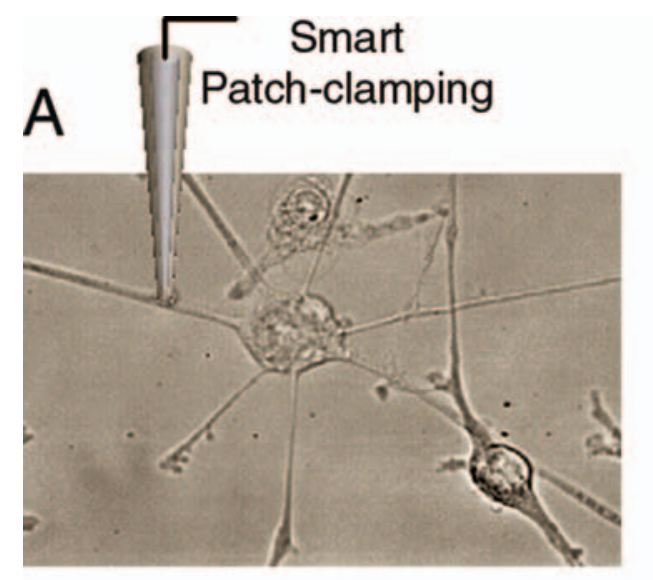

\section{C}
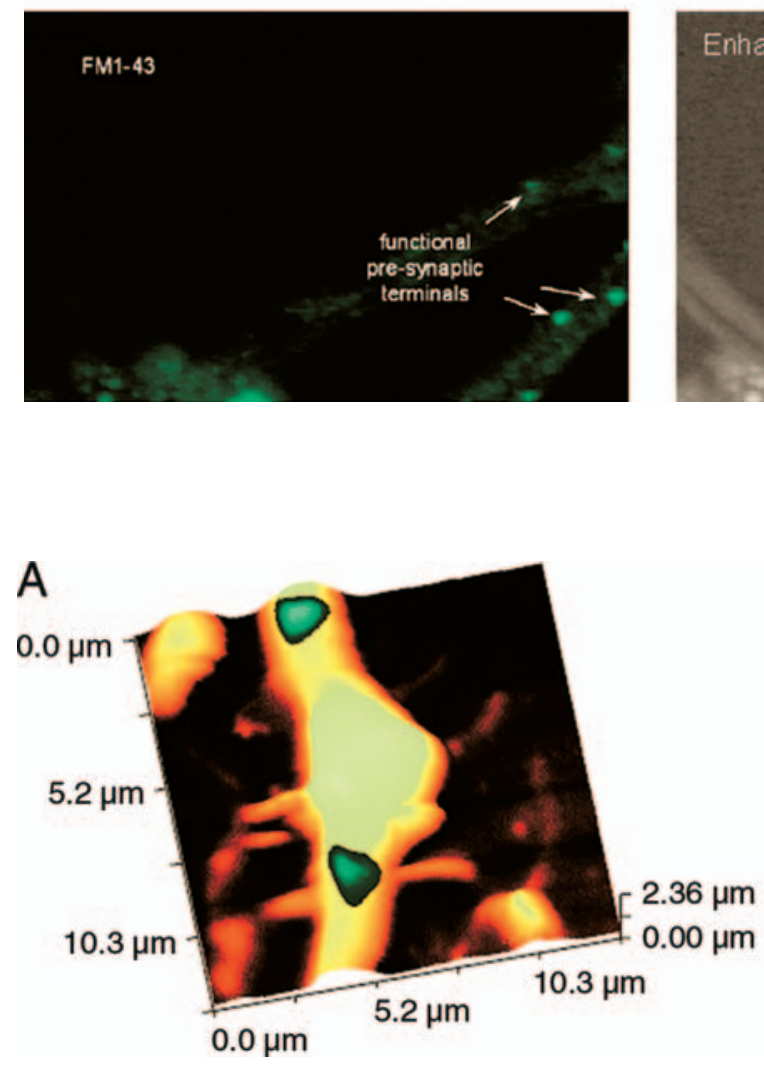

FIG. 5. hESC-derived neuronal cells (NCL1 line). (A) A topographical image showing a dendrite of hESC-derived neuronal cells (NCL1 line) combined with fluorescence from FM1-43 dye-filled vesicles. (B) hESC-derived neuronal cells (NCL1 line) after staining with tubulin III antibodies. (C) RT-PCR analysis of hESC-derived neuronal cells (NCL1 line). Markers: TH, tyrosine hydroxylase; BLBP, brain lipid binding protein; GLAST, glial high affinity glutamate transporter; EN1, engrailed homolog 1; NCAM, neural cell adhesion molecule; PAX6, paired box gene 6; NURR1, nur related protein 1; LMX1, LIM homeodomain transcription factor; HLXB9, homeo box HB9. Color images available online at www .liebertonline.com/ten.

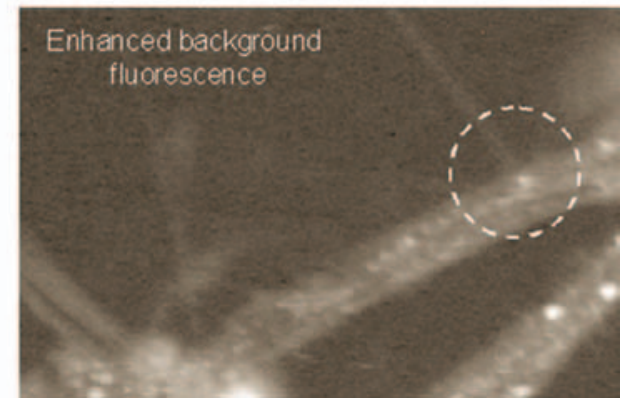

B
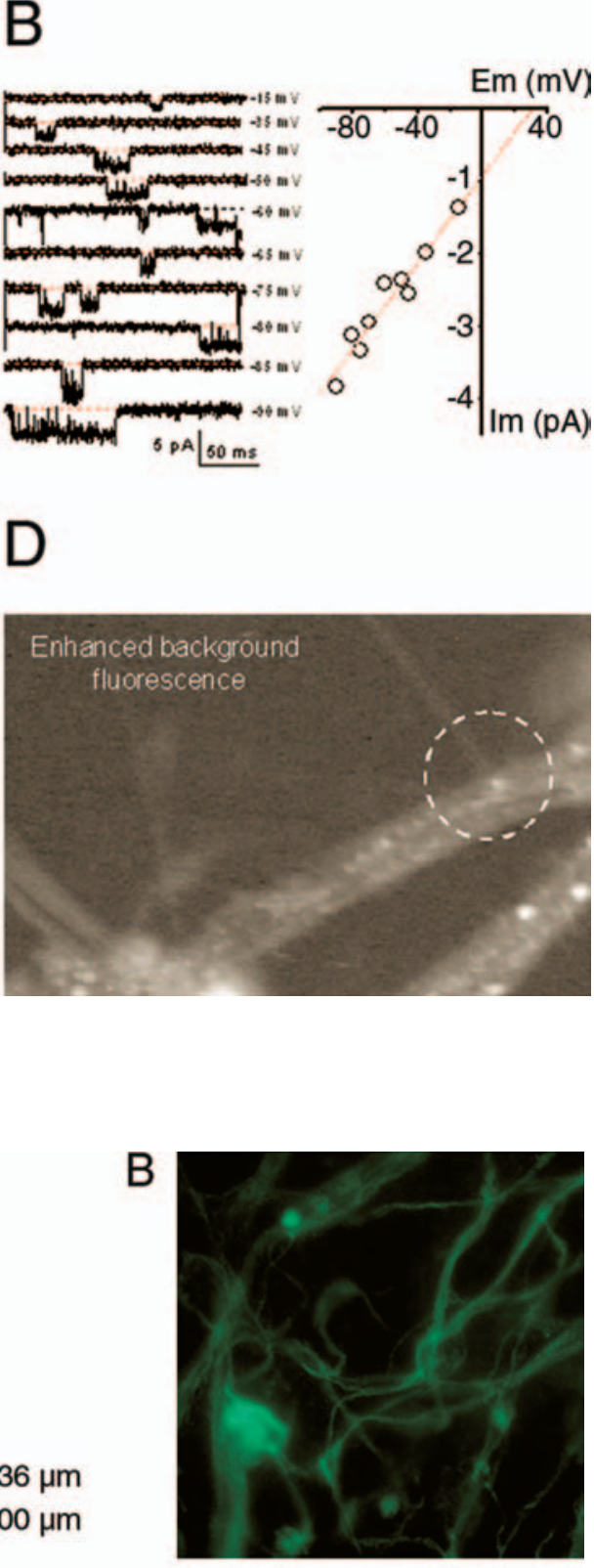

D

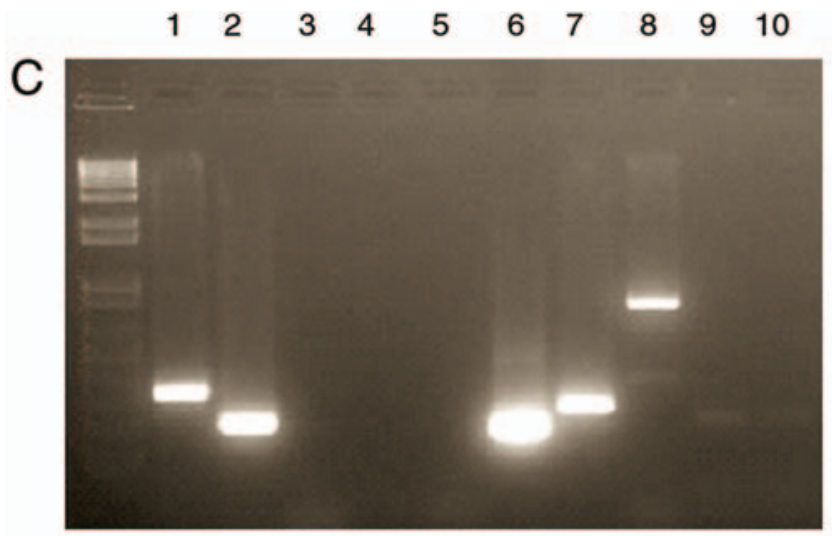

Neural markers: 1- TH; 2- Nestin; 3- BLBP; 4- GLAST; 5- EN1; 6- NCAM; 7-PAX6; 8- NURR1 9- LMX1; 10- HLXB9 
SICM image of the surface of a contracting ESCM from the same culture. Figure $3 \mathrm{C}$ confirms staining of these beating areas after fixation with anticardiac myosin heavy chain (MHC) marker.

We can study the contractile properties of a single cell by measuring the vertical displacement of the SICM pipette (depicted in Fig. 3D), as described previously. ${ }^{21,23} \mathrm{We}$ monitored the contraction of an individual cardiomyocyte noninvasively before and after the exposure to a number of agents that either modulate contraction or cause arrhythmias. Previously, we reported that the $\beta$-antagonist esmolol can restore rhythm in doxorubicin-treated cultures of neonatal rat cardiomyocytes ${ }^{28}$ and mouse ESCMs. ${ }^{23}$ Here, we studied the effect of esmolol on human embryonic stem cellderived cardiomyocytes (hESCM) that have been made to beat arrhythmically by prior incubation with doxorubicin. Figure 3E and 3F shows recordings of the contraction of a single ESCM within a cluster. Adding acutely high dose of doxorubicin $(100 \mu \mathrm{g} / \mathrm{mL})$ induces arrhythmia (Fig. 3E), and subsequent addition of esmolol $(1 \mu \mathrm{g} / \mathrm{mL})$ restores rhythmic contractions (Fig. 3F). This assay allowed, within the same experiment, the identification of all ESCMs within the layer, and an accurate measure of the response of any single ESCM.

Loading the cells with the calcium indicator Fluo-4 and using a combination of SICM and confocal microscopy, we can measure the local concentration of calcium ions simultaneously with the cell motion. ${ }^{21}$

\section{Study of SC-derived neurons}

We can also evaluate the degree of neuronal differentiation of SC-derived neurons. In general, studying neurons is hampered by the difficulties of assessment of the maturity of SC-derived neuronal cells. Using our technique of combined SICM and confocal microscopy, we can identify synapses in primary cultures of neurons and in cultures of SC-derived neuronal cells. We can then establish the degree of maturity of these synapses by performing standard patch-clamp recording of ion channels in the different regions of the SCderived neuronal cells. This is done using the same pipette that has been used to image the cells, as an electrophysiological patch pipette. The advantage here is that we combined high-resolution imaging with fluorescence microscopy and patch-clamp into a single set-up, thus enabling us to target the synapse and quickly assess the degree of differentiation of SCs into neurons.

Figure 4 shows possible evaluation of neuronal differentiation of neural crest-like SCs using SICM. Single-channel recording from neural crest-like SCs confirms the presence of a sodium-like channel (Fig. 4B). Staining with FM1-43 dye confirmed active synapses in sensory neurons derived from multipotent neural crest-like SCs (Fig. 4C, D). Thus, we can exploit our abilities to target synapses in fine dendrites, where major neuronal information processing occurs, and obtain detailed functional distribution of the key ion channels and receptors at the synapses. Further, we can probe how this distribution changes as SCs evolve in development and in the repair of nervous tissue.

Neuron-like cells were obtained after spontaneous neural differentiation of undifferentiated cells from the hES-NCL1 line. These cells exhibited neural characteristics both morphologically and by the expression of several key neural markers. The neural cell shape was measured using scanning ion conductance microscope. Figure 5A shows a topographical image of a dendrite of a neuron-like cell. Fluorescence from FM1-43 dye that was delivered to the vesicles was recorded at the same time from this area and is also shown in Figure 5A. Neuron-like cells were also stained positive with anti-tubulin III antibodies (Fig. 5B). Several neuronal protein $\mathrm{mRNAs}$ were detected in these neuron-like cells by RT-PCR analysis (Fig. 5C).

\section{Summary}

SICM and SICM-based techniques (SSCM and smart patch) are powerful tools to noninvasively characterize the physiology of undifferentiated and differentiated ESCs, including hESCs and non-ESCs.

Using these techniques, we can

1. Topographically image the surfaces of undifferentiated hESCs with high resolution (down to $20 \mathrm{~nm}$ ) for long periods (up to $48-72 \mathrm{~h}$ ) and study the surface as the cells differentiate.

2. Resolve small surface structures (microvilli and cilia) and study their dynamics.

3. Perform quality control of the hESC growth conditions. Using SSCM we can study the distribution of fluorescentlabeled differentiated markers on the surface of hESCs.

4. Identify individual beating ESCMs among the mixed cell types that exist in culture.

5. Nonintrusively measure the contraction and calcium dynamics of individual ESCM in situ at different stages of differentiation using a combination of SICM and confocal microscopy simultaneously.

6. Identify synapses in SC-derived neuronal cells.

7. Identify pre- and postsynaptic membrane.

8. By positioning of the scanning pipette probe, obtain a gigaseal for patch clamping.

9. Record single channels from different regions of the SCderived cells using smartpatch clamp.

Taken together, SICM-based techniques can be applied to noninvasively characterize and study the differentiation of SCs.

\section{Acknowledgments}

Research was supported by the Biotechnology and Biological Sciences Research Council; The National Centre for the Replacement, Refinement and Reduction of Animals in Research; University Technology Mara in Malaysia; One North East Developmental Agency; Wellcome Trust and the Royal Society. E.V.S. was supported by the Wellcome Trust (Grant 078310). We are grateful to Dario Melguizo for technical support.

\section{Disclosure Statement}

No competing financial interests exist.

\section{References}

1. Menendez, P., Bueno, C., and Wang, L. Human embryonic stem cells: a journey beyond cell replacement therapies. Cytotherapy 8, 530, 2006.

2. Paparella, M., Kolossov, E., Fleischmann, B.K., Hescheler, J., and Bremer, S. The use of quantitative image analysis in the 
assessment of in vitro embryotoxicity endpoints based on a novel embryonic stem cell clone with endoderm-related GFP expression. Toxicol In Vitro 16, 589, 2002.

3. zur Nieden, N.I., Cormier, J.T., Rancourt, D.E., and Kallos, M.S. Embryonic stem cells remain highly pluripotent following long term expansion as aggregates in suspension bioreactors. J Biotechnol 129, 421, 2007.

4. Zhang, X., Stojkovic, P., Przyborski, S., Cooke, M., Armstrong, L., Lako, M., and Stojkovic, M. Derivation of human embryonic stem cells from developing and arrested embryos. Stem Cells 24, 2669, 2006.

5. Gerrard, L., Zhao, D., Clark, A.J., and Cui, W. Stably transfected human embryonic stem cell clones express OCT4-specific green fluorescent protein and maintain selfrenewal and pluripotency. Stem Cells 23, 124, 2005.

6. Gepstein, L. Derivation and potential applications of human embryonic stem cells. Circ Res 91, 866, 2002.

7. van Hoof, D., Mummery, C.L., Heck, A.J., and Krijgsveld, J. Embryonic stem cell proteomics. Expert Rev Proteomics 3, 427, 2006.

8. Hansma, P.K., Drake, B., Marti, O., Gould, S.A., and Prater, C.B. The scanning ion-conductance microscope. Science 243, 641, 1989.

9. Korchev, Y.E., Bashford, C.L., Milovanovic, M., Vodyanoy, I., and Lab, M.J. Scanning ion conductance microscopy of living cells. Biophys J 73, 653, 1997.

10. Korchev, Y.E., Gorelik, J., Lab, M.J., Sviderskaya, E.V., Johnston, C.L., Coombes, C.R., Vodyanoy, I., and Edwards, C.R. Cell volume measurement using scanning ion conductance microscopy. Biophys J 78, 451, 2000.

11. Shevchuk, A.I., Frolenkov, G.I., Sanchez, D., James, P.S., Freedman, N., Lab, M.J., Jones, R., Klenerman, D., and Korchev, Y.E. Imaging proteins in membranes of living cells by high-resolution scanning ion conductance microscopy. Angew Chem Int Ed Engl 45, 2212, 2006.

12. Gorelik, J., Shevchuk, A.I., Frolenkov, G.I., Diakonov, I.A., Lab, M.J., Kros, C.J., Richardson, G.P., Vodyanoy, I., Edwards, C.R., Klenerman, D., and Korchev, Y.E. Dynamic assembly of surface structures in living cells. Proc Natl Acad Sci USA 100, 5819, 2003.

13. Stojkovic, P., Lako, M., Przyborski, S., Stewart, R., Armstrong, L., Evans, J., Zhang, X., and Stojkovic, M. Humanserum matrix supports undifferentiated growth of human embryonic stem cells. Stem Cells 23, 895, 2005.

14. Hyslop, L., Stojkovic, M., Armstrong, L., Walter, T., Stojkovic, P., Przyborski, S., Herbert, M., Murdoch, A., Strachan, T., and Lako, M. Downregulation of Nanog induces differentiation of human embryonic stem cells to extraembryonic lineages. Stem Cells 23, 1035, 2005.

15. Erceg, S., Lainez, S., Ronaghi, M., Stojkovic, P., Perez-Arago, M.A., Moreno-Manzano, V., Moreno-Palanques, R., PlanellsCases, R., and Stojkovic, M. Differentiation of human embryonic stem cells to regional specific neural precursors in chemically defined medium conditions. PLoS ONE 3, e2122, 2008.

16. Herrington, J., and Lingle, C.J. Kinetic and pharmacological properties of low voltage-activated $\mathrm{Ca} 2+$ current in rat clonal (GH3) pituitary cells. J Neurophysiol 68, 213, 1992.

17. Kostyuk, P.G., Krishtal, O.A., and Pidoplichko, V.I. Effect of internal fluoride and phosphate on membrane currents during intracellular dialysis of nerve cells. Nature 257, 691, 1975.

18. Todorovic, S.M., and Lingle, C.J. Pharmacological properties of T-type $\mathrm{Ca} 2+$ current in adult rat sensory neurons: effects of anticonvulsant and anesthetic agents. J Neurophysiol 79, 240, 1998.

19. Coste, B., Osorio, N., Padilla, F., Crest, M., and Delmas, P. Gating and modulation of presumptive NaV1.9 channels in enteric and spinal sensory neurons. Mol Cell Neurosci 26, 123, 2004

20. Maruyama, H., Yamamoto, M., Matsutomi, T., Zheng, T., Nakata, Y., Wood, J.N., and Ogata, N. Electrophysiological characterization of the tetrodotoxin-resistant $\mathrm{Na}+$ channel, $\mathrm{Na}(\mathrm{v}) 1.9$, in mouse dorsal root ganglion neurons. Pflugers Arch 449, 76, 2004.

21. Shevchuk, A.I., Gorelik, J., Harding, S.E., Lab, M.J., Klenerman, D., and Korchev, Y.E. Simultaneous measurement of $\mathrm{Ca} 2+$ and cellular dynamics: combined scanning ion conductance and optical microscopy to study contracting cardiac myocytes. Biophys J 81, 1759, 2001.

22. Gorelik, J., Shevchuk, A., Ramalho, M., Elliott, M., Lei, C., Higgins, C.F., Lab, M.J., Klenerman, D., Krauzewicz, N., and Korchev, Y. Scanning surface confocal microscopy for simultaneous topographical and fluorescence imaging: application to single virus-like particle entry into a cell. Proc Natl Acad Sci USA 99, 16018, 2002.

23. Gorelik, J., Ali, N.N., Shevchuk, A.I., Lab, M., Williamson, C., Harding, S.E., and Korchev, Y.E. Functional characterization of embryonic stem cell-derived cardiomyocytes using scanning ion conductance microscopy. Tissue Eng 12, 657, 2006.

24. Gorelik, J., Gu, Y., Spohr, H.A., Shevchuk, A.I., Lab, M.J., Harding, S.E., Edwards, C.R., Whitaker, M., Moss, G.W., Benton, D.C., Sanchez, D., Darszon, A., Vodyanoy, I., Klenerman, D., and Korchev, Y.E. Ion channels in small cells and subcellular structures can be studied with a smart patch-clamp system. Biophys J 83, 3296, 2002.

25. Gu, Y., Gorelik, J., Spohr, H.A., Shevchuk, A., Lab, M.J., Harding, S.E., Vodyanoy, I., Klenerman, D., and Korchev, Y.E. High-resolution scanning patch-clamp: new insights into cell function. FASEB J 16, 748, 2002.

26. Cui, L., Johkura, K., Yue, F., Ogiwara, N., Okouchi, Y., Asanuma, K., and Sasaki, K. Spatial distribution and initial changes of SSEA-1 and other cell adhesion-related molecules on mouse embryonic stem cells before and during differentiation. J Histochem Cytochem 52, 1447, 2004.

27. Krtolica, A., Genbacev, O., Escobedo, C., Zdravkovic, T., Nordstrom, A., Vabuena, D., Nath, A., Simon, C., Mostov, K., and Fisher, S.J. Disruption of apical-basal polarity of human embryonic stem cells enhances hematoendothelial differentiation. Stem Cells 25, 2215, 2007.

28. Gorelik, J., Vodyanoy, I., Shevchuk, A.I., Diakonov, I.A., Lab, M.J., and Korchev, Y.E. Esmolol is antiarrhythmic in doxorubicin-induced arrhythmia in cultured cardiomyocytesdetermination by novel rapid cardiomyocyte assay. FEBS Lett 548, 74, 2003

Address reprint requests to: Julia Gorelik, Ph.D.

National Heart and Lung Institute Imperial College London Guy Scadding Building, Dovehouse St. London SW3 6LY United Kingdom

E-mail: j.gorelik@imperial.ac.uk

Received: January 28, 2008 Accepted: June 21, 2008 